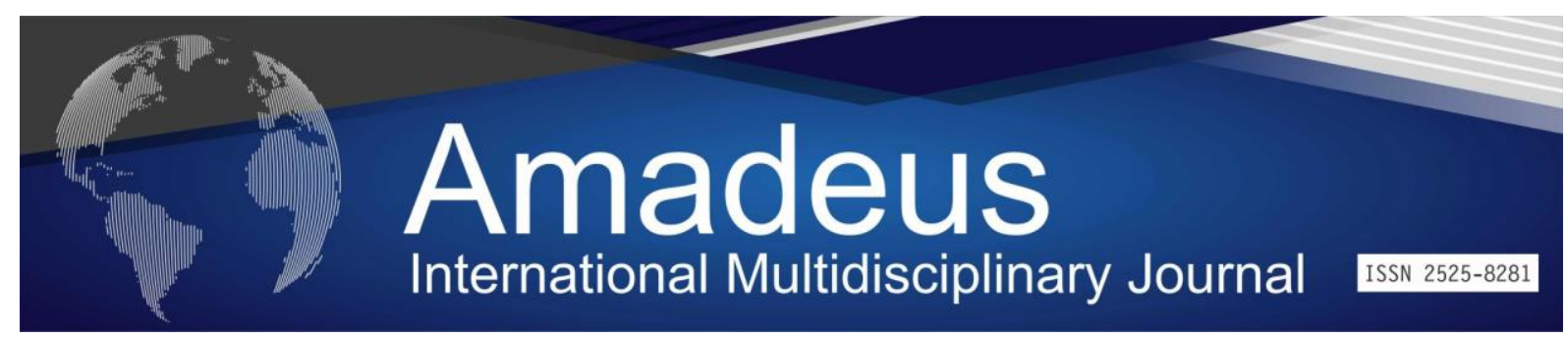

DOI: 10.14295/aimj.v5i9.148

\title{
Domestic Violence against Men: Simple Joy or pure Reality?
}

Maria Aparecida Feitosa Cândido Herculano ${ }^{\text {; }}$ Allex Alves Sobral de Sousa ${ }^{2}$;

Carmelita Maria Silva Sousa ${ }^{3}$; Iasmin Belém Silva Queiroz ; Maria Zildanê Cândido Feitosa Pimentel ${ }^{5}$; Maria Nailê Cândido Feitoza de Lima; João Pedro Cândido

Pimentel $^{7}$;

Carolina Cândido Dominguês ${ }^{8}$; Willma José de Santana ${ }^{9}$; Dayse Christina Rodrigues Pereira Luz ${ }^{10}$.

\begin{abstract}
Objective: To describe data on domestic violence against men. Method: This is an integrative literature review, carried out in the Scientific Electronic Electronic Library Online (SciELO), LILACS, and Capes Acadêmico portal between the years 2015 and 2020, with articles published in Portuguese, English and Spanish. 456 articles were found, of which 8 were selected and used in this review. The results showed that the man is also a victim of domestic violence suffering physical, psychological and sexual aggression. The aggressors are wives, mothers, sisters and daughters. Among the men attacked are husbands, brother children and sometimes the father himself. Men who are victims of domestic violence do not seek justice for two reasons: a) they do not believe that legal measures are taken, b) a complaint would expose them to society, which would be humiliating for them. Another important data from the results shows that the Maria da Penha Law, which supports women who are victims of men's violence, is not applicable when the actors are the same, however, the roles are reversed. Final considerations: Studies on this theme are scarce, which suggests the realization of new research as it is a subject of recognized scientific and social relevance.
\end{abstract}

Keywords: Gender-based violence. Domestic violence. Genre. Man.

\footnotetext{
${ }^{1}$ Master's student in Public Policy at Universidade Athenas College. Email: cidinhacandido@gmail.com;

${ }^{2}$ Master's student in Public Policy at Universidade Athenas College. Email: allexsobralfisio@ hotmail.com;

${ }^{3}$ Master's student in Public Policy at Universidade Athenas College. Email: carmelitasilva11@ @otmail.com;

${ }^{4}$ Master's student in Public Policy at Universidade Athenas College. Email: iasminbelem @ hotmail.com;

${ }^{5}$ Master in Public Policies with emphasis on Health at Universidade Athenas College. Professor at the University Center Lion Sampaio - UNILEÃO Email: zildinhapimentel@gmail.com;

${ }^{6}$ Master in Planning and Public Policy from the State University of Ceará - UECE, and Professor at Centro Universitário de Juazeiro do Norte - UNIJUAZEIRO. Email: nailecandido@ hotmail.com;

${ }^{7}$ Graduated in Law from the Centro Universitário Paraíso - UNIFAP. Email: 097joaopedro@ gmail.com;'

${ }^{8}$ Postgraduate in Criminal Law and Criminology from the Regional University of Cariri - URCA. Email: carolcd09@gmail.com;

${ }^{9}$ Post Doctoral Student in Health Sciences - FMABC, PhD in Biological Sciences at UFPE and Professor at Centro Universitário de Juazeiro do Norte - UNIJUAZEIRO and Faculty of Technology - FATEC - CARIRI. Email:wjsantana@hotmail.com;

${ }^{10}$ Post Doctoral Student in Health Sciences at the Health University Center of ABC-FMABC, Professor at the University Center of Juazeiro do Norte - UNIJUAZEIRO. Email: dayse.dcrp@ hotmail.com.
} 


\title{
Violência Doméstica contra os Homens: Simplória Alegoria ou pura Realidade?
}

\begin{abstract}
Resumo: Objetivo: Descrever os dados sobre violência doméstica contra os homens. Método: Trata-se de uma revisão integrativa da literatura, realizada nas bases de dados Scientific Eletronic Library Online (SciELO), LILACS, e portal Capes Acadêmico entre os anos de 2015 e 2020, com artigos publicados nos idiomas português inglês e espanhol. Foram encontrados 456 artigos dos quais 8 foram selecionados e utilizados nesta revisão. Os resultados mostraram que o homem também é vítima da violência doméstica sofrendo agressões físicas, psicológicas e sexuais. As agressoras são esposas, mães, irmãs e filhas. Entre os homens agredidos estão maridos, filhos irmãos e às vezes o próprio pai. Homens vítimas da violência doméstica, não recorrem à justiça por dois motivos: a) não acreditam que providências legais sejam tomadas, b) uma denúncia os exporia à sociedade o que para eles seria humilhante. Outro importante dado advindo dos resultados mostra que a Lei Maria da Penha, que ampara a mulher vítima da violência do homem, não tem aplicabilidade quando os atores são os mesmos, porém, os papéis se invertem. Considerações finais: Estudos acerca desta temática são escassos, o que sugere a realização de novas pesquisas por ser um assunto de reconhecida relevância científica e social.
\end{abstract}

Palavras-chave: Violência de gênero. Violência doméstica. Gênero. Homem.

\section{Introdução}

O conceito de violência é amplo e complexo e implica em vários elementos e definições teóricas além de diversas formas de solução e erradicação (Arblaster et al, 1996). De maneira geral a mesma pode ser definida como uso e abuso de poder de forma agressiva, utilizando da força física ou psicológica (Paviani et al, 2007).

Agressões sofridas por mulheres e homens são designadas de violência de gênero, isso porque culturalmente, a sociedade comumente percebe as relações entre o homem e mulher considerando o poder que cada um assume socialmente (Couto \& Schraiber, 2011).

Situações de enfurecimento, raiva e outras similares, implicam em atos violentos e impetuosos que ensejam uma diversidade de subtemas a serem trabalhados. Neste artigo é tratada especificamente a violência doméstica praticada por mulheres contra os homens, 
sejam eles, cônjuges, pais, irmãos, filhos, enteados. Trata-se de uma realidade vivenciada, porém, nem sempre divulgada, uma vez que pessoas do gênero masculino também são vítimas de agressões no espaço intrafamiliar e extrafamiliar mesmo que os registros mostrem que isso ocorre com menor incidência (Lopes et al, 2016).

Quando o assunto é violência doméstica Dotoli e Leão (2015), relatam que geralmente as denúncias fazem referência a homens que agridem mulheres. Mas se ao contrário for, e a situação envolver um denunciante e uma denunciada, certamente será um fato a causar espanto, pois esse tipo de denúncia não é comum. Diferente da mulher que tem como e onde recorrer a medidas de proteção, o homem ainda precisa buscar políticas públicas que o ampare em situações de violência doméstica. Nesse sentido, juízes tentam encontrar na Lei Maria da Penha, abertura que possa ser aplicada em defesa do gênero masculino.

Diante desta realidade pergunta-se: Na literatura que versa sobre violência doméstica, existem dados que mostrem o homem no papel de vítima e não de agressor? Para responder ao questionamento proposto, o objetivo desta pesquisa foi descrever dados sobre violência doméstica contra os homens.

\section{Metodologia}

O presente estudo consiste numa revisão integrativa, no qual a amostra foi construída a partir de artigos publicados em mídia online, visando a melhor observação do tema abordado, qual seja, dados relacionados a violência doméstica tendo o gênero masculino como vítima e não como agressor. Sousa, Silva e Carvalho (2010), atribuem a esse tipo de revisão o mais alto grau de abrangência dentre as revisões, propiciando dessa forma uma melhor compreensão geral do estudo a partir da inclusão dos diferentes delineamentos metodológicos, fazendo uso de informações da literatura teórica e empírica.

Trata-se de uma revisão integrativa da literatura cuja finalidade foi buscar em artigos revisados dados relacionados a violência doméstica cuja vítima fosse a figura masculina. A busca nas bases de dados se deu considerando a seguinte questão de pesquisa: Na literatura que versa sobre violência doméstica, existem dados que mostrem o homem no papel de vítima e não de agressor?

Para coleta dos dados foram realizadas buscas nas bases de dados Scientific Eletronic Library Online (SciELO), LILACS e o portal Capes Acadêmico. Os critérios de inclusão 
foram: artigos escritos em português, inglês e espanhol, publicados na íntegra, de forma gratuita e entre os anos de 2015 e 2020, em revistas ou periódicos, artigos do tipo: estudos de observação, ensaios clínicos, e ainda a chamada literatura cinzenta. A busca e seleção do material utilizado nesta revisão aconteceu entre maio a julho de 2020, o levantamento dos artigos ocorreu a partir dos seguintes descritores em saúde contidos no DeCS/MeSH: Violence; Domestic Violence; Gender Identity fazendo o cruzamento com o operador booleano AND e as palavras chaves foram: Violência de gênero, Violência doméstica, Gênero, Homem e todos os descritores.

A seleção dos artigos foi realizada a partir de uma leitura prévia considerando o título e o resumo, e em seguida foi realizada uma leitura minuciosa dos já selecionados observando àqueles que respondiam à questão norteadora e consequentemente atendiam ao objetivo da pesquisa. Os dados foram extraídos e analisados por objetivação amostral e de dados presentes nos estudos. Como se trata de uma revisão de literatura e seguindo as recomendações da resolução 466/12 e 510/16 em pesquisas fundamentadas em bases de dados, não há necessidade de apreciação ética.

\section{Resultados e Discussão}

Depois deste processo chegou-se a um total de 456 artigos, sendo que após a leitura na íntegra de cada um, foram considerados e registrados neste estudo um total de 8 estudos, os quais estão apresentados na (Figura 1). 
Figura 1 - Fluxograma mostrando a seleção dos artigos incluídos na revisão.

Registros identificados por meio de pesquisa de banco de dados $(\mathrm{n}=456)$

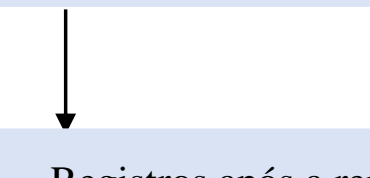

Registros após a remoção de duplicatas

$$
(\mathrm{n}=10)
$$

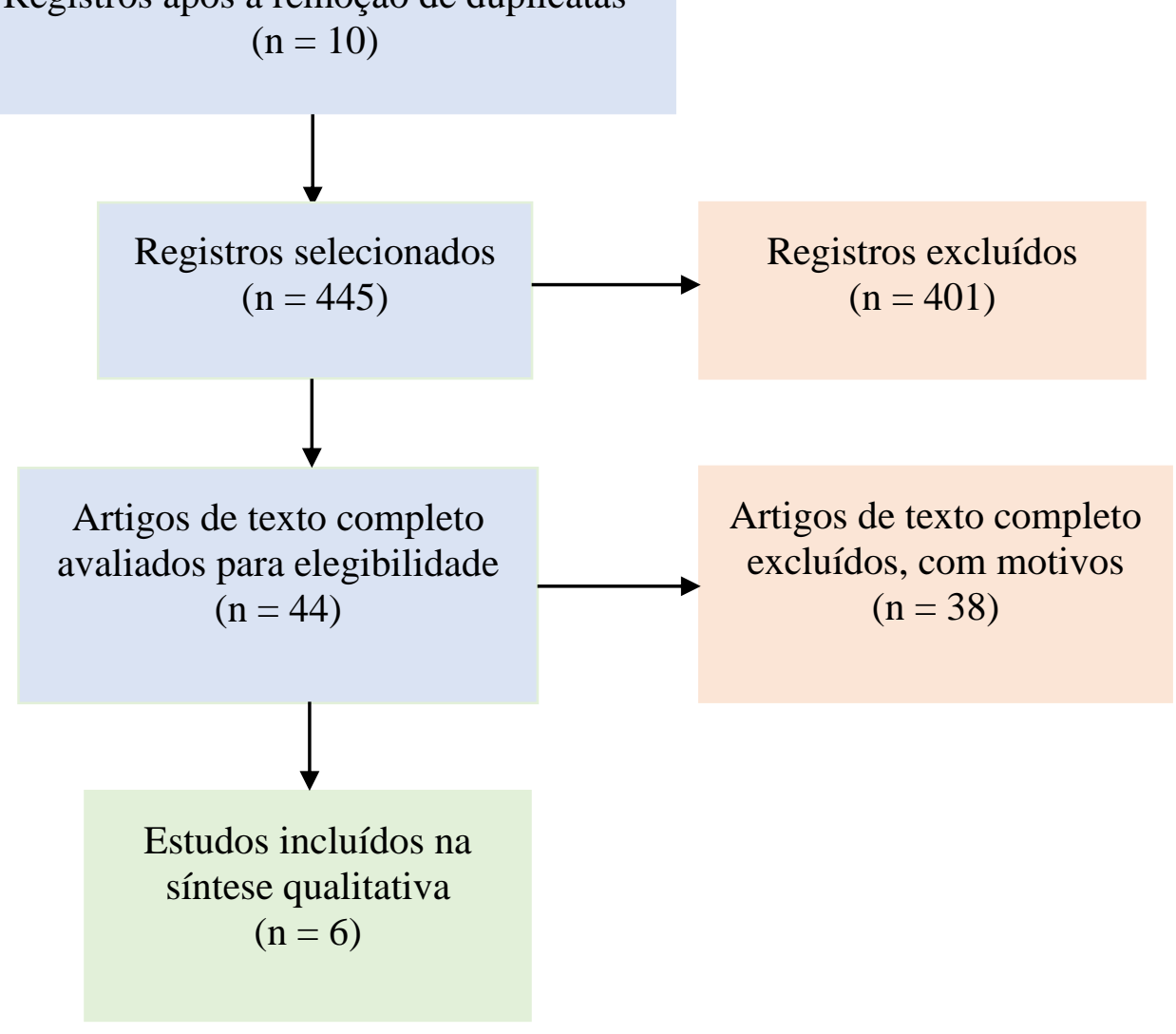

Registros adicionais identificados por outras fontes

$$
(n=0)
$$

Fonte: dados da Pesquisa, 2020. 
O quadro a seguir apresenta os resultados de 08 artigos selecionados, apresentando as principais características de cada um, correlacionadas com o tema do estudo, o (Quadro 1) contém os seguintes tópicos: Autor(s)/Ano, Título, Objetivos, Metodologia e Conclusão.

Quadro 1 - Síntese dos artigos incluídos na revisão integrativo.

\begin{tabular}{|c|c|c|c|c|}
\hline $\begin{array}{c}\text { Autore(s) / } \\
\text { (ano) }\end{array}$ & Título & Objetivos & Metodologia & Conclusão \\
\hline $\begin{array}{l}\text { Cezario, et } \\
\text { al. / (2015) }\end{array}$ & $\begin{array}{l}\text { A violência } \\
\text { entre } \\
\text { parceiros } \\
\text { íntimos sob a } \\
\text { perspetiva de } \\
\text { homens } \\
\text { vítimas de } \\
\text { suas parceiras } \\
\text { no Brasil }\end{array}$ & $\begin{array}{c}\text { Fazer um } \\
\text { levantamento } \\
\text { das informações } \\
\text { acerca da } \\
\text { violência contra } \\
\text { o homem no } \\
\text { município de } \\
\text { Juiz de Fora } \\
\text { (Brasil); } \\
\text { perceber se } \\
\text { existem homens } \\
\text { vítimas na } \\
\text { localidade e que } \\
\text { tipo de violência } \\
\text { sofrem. E quais } \\
\text { as dificuldades } \\
\text { por parte dos } \\
\text { homens em não } \\
\text { se reconhecerem } \\
\text { como vítimas. }\end{array}$ & $\begin{array}{c}\text { Estudo } \\
\text { Exploratório. } \\
\text { Pesquisa } \\
\text { Qualitativa. } \\
\text { Entrevistas } \\
\text { semiestruturadas; } \\
\text { Questionário } \\
\text { Sociodemográfico; } \\
\text { estatística } \\
\text { descritiva e Análise } \\
\text { de Conteúdo de } \\
\text { Bardin }\end{array}$ & $\begin{array}{l}\text { A violência psicológica } \\
\text { como a agressão mais } \\
\text { sofrida entre os } \\
\text { entrevistados seguidos } \\
\text { da violência física. Os } \\
\text { problemas afetivos, as } \\
\text { motivações abrangentes } \\
\text { e os problemas } \\
\text { socioeconômicos são } \\
\text { mencionados como os } \\
\text { principais motivadores. } \\
\text { Apenas } 38.46 \% \text { dos } \\
\text { homens vítimas } \\
\text { declararam ter procurado } \\
\text { ajuda e } 62.50 \% \text { alegaram } \\
\text { ainda ter contato com a } \\
\text { agressora. }\end{array}$ \\
\hline $\begin{array}{l}\text { Cecchetto, } \\
\text { et al. / } \\
(2016)\end{array}$ & $\begin{array}{c}\text { Violências } \\
\text { percebidas } \\
\text { por homens } \\
\text { adolescentes } \\
\text { na interação } \\
\text { afetivo-sexual } \\
\text { em dez } \\
\text { cidades } \\
\text { brasileiras }\end{array}$ & $\begin{array}{c}\text { Analisar as } \\
\text { visões e as } \\
\text { experiências de } \\
\text { jovens do sexo } \\
\text { masculino sobre } \\
\text { seus } \\
\text { relacionamentos, } \\
\text { explorando as } \\
\text { questões de } \\
\text { gênero e } \\
\text { violência entre } \\
\text { namorados } \\
\text { adolescentes. }\end{array}$ & $\begin{array}{c}\text { O presente artigo } \\
\text { baseia-se nas } \\
\text { informações } \\
\text { qualitativas que } \\
\text { buscaram } \\
\text { apreender as } \\
\text { opiniões, crenças e } \\
\text { valores sobre } \\
\text { violência no } \\
\text { namoro entre os } \\
\text { adolescentes. } \\
\text { Optou-se por } \\
\text { privilegiar as } \\
\text { visões mais amplas } \\
\text { sobre o tema para } \\
\text { captar as } \\
\text { representações } \\
\text { sociais do grupo } \\
\text { para além de } \\
\text { vivências }\end{array}$ & $\begin{array}{l}\text { Os resultados do estudo } \\
\text { mostram que os } \\
\text { significados atribuídos } \\
\text { ao fenômeno da } \\
\text { violência no namoro são } \\
\text { recortados por } \\
\text { representações rígidas de } \\
\text { papéis de gênero, } \\
\text { correspondendo às } \\
\text { expectativas em relação } \\
\text { ao desempenho de } \\
\text { homens e mulheres nas } \\
\text { relações afetivo-sexuais. }\end{array}$ \\
\hline
\end{tabular}




\begin{tabular}{|c|c|c|c|c|}
\hline & & & individuais & \\
\hline $\begin{array}{c}\text { Dotoli e } \\
\text { Leão / } \\
(2015)\end{array}$ & $\begin{array}{l}\text { Violência } \\
\text { doméstica } \\
\text { contra o } \\
\text { homem: de } \\
\text { agressor a } \\
\text { agredido }\end{array}$ & $\begin{array}{l}\text { Apreender o } \\
\text { significado de } \\
\text { género. } \\
\text { Problematizar a } \\
\text { existência das } \\
\text { denúncias por } \\
\text { parte dos } \\
\text { homens. Dar } \\
\text { resposta às } \\
\text { solicitações na } \\
\text { área da saúde } \\
\text { para apoio às } \\
\text { vítimas } \\
\text { masculinas. } \\
\text { Incentivar ao } \\
\text { repensar do } \\
\text { plano legal }\end{array}$ & $\begin{array}{c}\text { Pesquisa } \\
\text { Qualitativa. Estudo } \\
\text { Documental (Ficha } \\
\text { de Notificação de } \\
\text { Violência } \\
\text { Interpessoal/ Auto } \\
\text { provocada do } \\
\text { Ministério da } \\
\text { Saúde do Brasil }\end{array}$ & $\begin{array}{l}\text { Apesar das denúncias, o } \\
\text { silêncio ainda é uma } \\
\text { forma de defesa do } \\
\text { agredido. Nesse sentido, } \\
\text { aquando chamados para } \\
\text { entrevista, as vítimas } \\
\text { disseram que apenas } \\
\text { falaram para expor a } \\
\text { situação, por temor, } \\
\text { contudo "o evento não } \\
\text { necessitava ser } \\
\text { explicitadas e } \\
\text { intervindas em qualquer } \\
\text { tipo de ação para } \\
\text { promoção de saúde". Há } \\
\text { relutância em assumir a } \\
\text { própria denúncia. }\end{array}$ \\
\hline $\begin{array}{l}\text { Lopes, et } \\
\text { al. / (2016) }\end{array}$ & $\begin{array}{l}\text { Violência } \\
\text { doméstica } \\
\text { contra } \\
\text { homens: } \\
\text { perceções das } \\
\text { forças de } \\
\text { segurança. }\end{array}$ & $\begin{array}{l}\text { Compreender as } \\
\text { perceções das } \\
\text { forças de } \\
\text { segurança } \\
\text { relativamente à } \\
\text { violência } \\
\text { doméstica contra } \\
\text { os homens, } \\
\text { exercida em } \\
\text { relações } \\
\text { heterossexuais }\end{array}$ & $\begin{array}{c}\text { Metodologia } \\
\text { quantitativa } \\
\text { (estatística } \\
\text { descritiva e } \\
\text { estatística } \\
\text { inferencial) - } \\
\text { Inventário online } \\
\text { junto de } 1653 \\
\text { profissionais da } \\
\text { Guarda Nacional } \\
\text { Republicana e } \\
\text { Polícia de } \\
\text { Segurança Pública. }\end{array}$ & $\begin{array}{l}\text { Num estudo realizado no } \\
\text { Instituto de Medicina } \\
\text { Legal (n=535), } 11,5 \% \\
\text { dos casos avaliados } \\
\text { correspondiam a vítimas } \\
\text { do sexo masculino, cuja } \\
\text { perpetradora era mulher } \\
\text { e, havendo um historial } \\
\text { de violência física e } \\
\text { psicológica na maioria } \\
\text { dos casos (81,6\%).Em } \\
\text { 2015 (APAV) foram } \\
\text { recebidos } 388 \text { pedidos de } \\
\text { ajuda de homens vítimas } \\
\text { de VD, em relações } \\
\text { heterossexuais, } \\
\text { maioritariamente } \\
\text { casados (50,2\%), com } \\
\text { ensino superior (48,7\%), } \\
\text { empregados (54,2\%) } \\
\text { mantendo, atualmente, } \\
\text { uma relação conjugal } \\
\text { com a perpetradora } \\
\text { (50,8\%:APAV, 2016). } \\
\text { Os homens vítimas não } \\
\text { admitem sua condição e } \\
\text { não procuram ajuda } \\
\text { profissional, devido a } \\
\text { obstáculos sociais e à } \\
\text { falta de apoio. }\end{array}$ \\
\hline Souza e & A violência & Analisar a & Pesquisa & A violência doméstica \\
\hline
\end{tabular}




\begin{tabular}{|c|c|c|c|c|}
\hline $\begin{array}{c}\text { Ferreira / } \\
(2017)\end{array}$ & $\begin{array}{c}\text { doméstica } \\
\text { contra } \\
\text { homens no } \\
\text { Brasil: análise } \\
\text { da Proteção } \\
\text { sócio-jurídica } \\
\text { e das formas } \\
\text { de } \\
\text { enfrentamento }\end{array}$ & $\begin{array}{c}\text { violência } \\
\text { doméstica contra } \\
\text { homens no } \\
\text { Brasil à luz do } \\
\text { suporte } \\
\text { sóciojurídico e } \\
\text { das medidas } \\
\text { protetivas. }\end{array}$ & $\begin{array}{c}\text { exploratória e } \\
\text { qualitativa, de } \\
\text { cunho documental } \\
\text { e bibliográfico, que } \\
\text { se destina a } \\
\text { "aprofundar-se no } \\
\text { mundo dos } \\
\text { significados das } \\
\text { ações e relações } \\
\text { humanas, um lado } \\
\text { não perceptível e } \\
\text { não captável em } \\
\text { equações, médias e } \\
\text { estatísticas" }\end{array}$ & $\begin{array}{c}\text { contra o homem merece } \\
\text { ser enfrentada e } \\
\text { discutida, pela academia } \\
\text { e sociedade junto aos } \\
\text { órgãos governamentais, } \\
\text { buscando criar políticas } \\
\text { públicas que } \\
\text { contemplem o homem } \\
\text { em situação de violência } \\
\text { e a preservação da } \\
\text { integridade física do } \\
\text { mesmo, e criação de rede } \\
\text { de apoio à vítima. }\end{array}$ \\
\hline $\begin{array}{l}\text { Rauen e } \\
\text { Rauen / } \\
(2018)\end{array}$ & $\begin{array}{l}\text { Extensão do } \\
\text { Escopo da Lei } \\
\text { Maria da } \\
\text { Penha A } \\
\text { Homens } \\
\text { Vítimas de } \\
\text { Violência } \\
\text { Doméstica e } \\
\text { Familiar em } \\
\text { Pelicani } \\
\text { (2007): Uma } \\
\text { Análise } \\
\text { Pragmático- } \\
\text { Cognitiva }\end{array}$ & $\begin{array}{l}\text { Analisar através } \\
\text { de um viés } \\
\text { pragmático } \\
\text {-cognitivo, a } \\
\text { extensão do } \\
\text { escopo da Lei } \\
\text { Maria } \\
\text { da Penha a } \\
\text { homens vítimas } \\
\text { de violência } \\
\text { doméstica e } \\
\text { familiar }\end{array}$ & $\begin{array}{c}\text { Metodologia } \\
\text { descritiva e } \\
\text { explanatória } \\
\text { orientada pelas } \\
\text { noções teóricas de } \\
\text { conciliação de } \\
\text { metas de Rauen } \\
\text { (2014) e de } \\
\text { relevância de } \\
\text { Sperber e Wilson } \\
\text { (1986, 1995), } \\
\text { estabelecendo } \\
\text { correlações entre a } \\
\text { Constituição } \\
\text { Federal de 1988, a } \\
\text { Lei Maria da Penha } \\
\text { e o texto de } \\
\text { Pelicani }\end{array}$ & $\begin{array}{c}\text { Desse modo, conciliam- } \\
\text { se progressivamente as } \\
\text { submetas de harmonizar } \\
\text { a Lei à Constituição, } \\
\text { estender seu escopo a } \\
\text { vítimas masculinas e } \\
\text { proteger vítimas de } \\
\text { violência doméstica e } \\
\text { familiar } \\
\text { independentemente de } \\
\text { sexo e opção afetiva. } \\
\text { Aspecto completamente } \\
\text { diferente, todavia,é se } \\
\text { essa linha de } \\
\text { argumentação será } \\
\text { acolhida pelos leitores } \\
\text { em geral e pelos } \\
\text { operadores do Direito } \\
\text { em particular - } \\
\text { heteroconciliação. Essa } \\
\text { é, contudo, uma questão } \\
\text { que extrapola os } \\
\text { objetivos deste trabalho } \\
\text { em particular }\end{array}$ \\
\hline
\end{tabular}

Fonte: dados da Pesquisa, 2020.

Os resultados advindos dos artigos estudados mostram que a violência sorrateiramente ou alardeada está presente em meio a muitas famílias brasileiras, e que o homem por vezes passa de agressor a agredido. De algoz a vítima.

As agressões no contexto familiar podem ser protagonizadas tanto pelo homem como pela mulher. Dependendo da ocasião e da relação de poder entre os dois, em momentos 
diferentes a mulher é quem agride e essa agressão é direcionada vezes ao marido, ao filho ou ao próprio pai. Essas agressões podem partir de pessoas de diferentes idades, mostrando que os agressores não pertencem a um único gênero e podem ser de diferentes idades (Ferreira et al, 2019).

Nos resultados apresentados do estudo de Rauen e Rauen (2018), encontra-se um comentário acerca do Art. $5^{\circ}$ da Lei Maria da Penha, quando dissertam que não sendo a vítima de agressão uma mulher, conclui-se por negação a inaplicabilidade desta, a conflitos cuja vítima seja o homem. Percebe-se destaque para o fato de que a Constituição tem no princípio da igualdade a premissa legal de que todos são iguais perante a lei, e assim, não só a mulher, mas, também o homem deve ser protegido, amparado, e apoiado e casos de violência doméstica.

Na pesquisa de Barros e Schraiber (2011), cujo propósito foi analisar as violências não fatais sofridas e praticadas por homens e mulheres adultos, em situação de parceria íntima, os resultados trazem a mostra diferenças de gênero muito importante quando se volta o olhar para a prevalência das violências como também a percepção que se tem destas quando a vítima é mulher ou homem.

O estudo realizado por Souza e Ferreira (2017), sugere que a violência contra o homem deve ser discutida pela academia chamando atenção da sociedade e do Estado de forma que ações possam ser pensadas e transformadas em Políticas Públicas que favoreça o homem. Nesse sentido deve ser criada uma rede de apoio que trabalhe em função de compreender esse fenômeno em um contexto amplo e assim promova-se reflexões e discussões.

Lopes et al (2016), apresenta dados de um estudo realizado no Instituto de Medicina Legal ( $\mathrm{n}=535$ ), mostrando que $11,5 \%$ dos casos avaliados correspondiam a vítimas do sexo masculino, agredidos pela mulher, e que na maior parte dos registros a violência cometida era física e psicológica, chegando a um percentual de (81,6\%). Outro dado importante a ser ressaltado mostra que em 2015 (APAV) recebeu 388 pedidos de ajuda de homens vítimas de $\mathrm{VD}$, em relações heterossexuais, maioritariamente casados (50,2\%), com ensino superior (48,7\%), empregados (54,2\%) mantendo, atualmente, uma relação conjugal com a perpetradora. Também neste estudo foi destacado que os homens agredidos por suas parceiras não admitem sua condição e não buscam ajuda, pois se intencionarem fazer, se depararão com impeditivos sociais e ausência de apoio. 
Em Cecchetto et al (2016), os resultados do estudo mostram que a expectativa de significativa parcela da sociedade vê os papéis desempenhados por cada gênero como algo rígido, atribuindo uma caraterística peculiar ao homem e a mulher em suas relações afetivosexuais. Mostra ainda a necessidade de repensar essa associação comumente feita entre violência e masculinidade entendendo que a primeira não deve ser considerada um atributo natural a ser ostentado pelo homem.

Em Dotoli e Leão (2015), os resultados evidenciam que pessoas vítimas de violência doméstica muitas vezes relutam em denunciar e buscar ajuda. Para estas, o ficar em silencio é uma maneira de se protegerem. A não exposição da agressão é uma alternativa de se resguardarem, em outros momentos até expõem, mas unicamente com o propósito de compartilhar aquele episódio de modo a "desabafar" com alguém.

Para Cezario et al (2015), nas falas dos participantes de sua pesquisa, os entrevistados demonstraram que a violência psicológica é o tipo de agressão mais praticado, depois vem a violência física. Quanto as causas das agressões foram apontadas aquelas que relacionadas a problemas afetivos, socioeconômicos, como as principais. Destaca-se neste estudo o fato de somente $38.46 \%$ dos homens vítimas declararam ter procurado ajuda e $62.50 \%$ alegaram ainda ter contato com a agressora. Afirmam ainda a existência de violência perpetrada pelas companheiras, no entanto o companheiro agredido não se sente bem em falar sobre a situação vivenciada.

Todos esses artigos analisados trazem uma verdade já há muito conhecida: o homem também é vítima de agressões por parte de sua parceira ou parceiro. No entanto a visibilidade dada a esse tipo de situação, por ser em menor número que a violência contra a mulher, ou porque na cultura machista o homem não admite que a mulher o agrediu, os registros se comparados com a violência contra o gênero feminino é bem menor. Adicionado a esta realidade pode-se afirmar também que em termos de Políticas Públicas de proteção ao gênero masculino, muito ainda precisa ser discutido e realizado.

Quando os casos de violência trazem o homem como a vítima da agressão sofrida, torna-se mais difícil para os profissionais de saúde identificar e registrar nos prontuários. Isso se deve ao fato de que os homens não são tidos como potenciais vítimas de agressão por suas parceiras ou parceiros. Essa realidade decorre do olhar da sociedade em relação ao gênero, num cenário no qual a mulher é tida como submissa ao homem. Como consequência desse olhar, não se percebe o homem como vítima de agressão, mas sim e sempre, como o agressor. 


\section{Considerações Finais}

Esta revisão respondeu ao questionamento proposto atingindo assim o objetivo do estudo, vez que os resultados comprovaram a existência de dados significativos sobre a violência contra o homem, apesar de que em grande parte dos casos não são notícias ou não se constituem em casos veiculados na mídia.

Por fim, este estudo poderá servir como base para discussões e reflexões acerca da violência de gênero e assim prestar relevante contribuição no sentido de instigar a busca por medidas protetivas também em relação ao gênero masculino vítima da violência intrafamiliar e extrafamiliar. Sugere-se que novas pesquisas possam ser realizadas contribuindo assim para a ampliação de publicações sobre o assunto.

\section{Referências}

Arblaster M. T. et al. (1996). Violência. In: Outhwaite W.; Bottomore T. Dicionário do Pensamento Social no Século XX. In: São Paulo: Jorge Zahar Editor, p. 803-804.

Barros C. R. D. S. \& Schraiber L. B. (2017). Intimate partner violence reported by female and male users of healthcare units. Rev Saude Publica, v. 16, n. 51, p. 7-11.

Cecchetto F. et al. (2016). Violências percebidas por homens adolescentes na interação afetivo-sexual em dez cidades Brasileiras. Interface Commun Heal Educ, v. 9, n. 2, p. 1429.

Cezario F. C. et al. (2015). A violência entre parceiros íntimos sob a perspectiva de homens vítimas de suas parceiras no Brasil. Perspectivas en Psicología: Revista de Psicología y Ciencias Afines, v. 12, n. 7, p. 34-46.

Couto M. \& Schraiber L. (2011). Representações da violência de gênero para homens e perspectivas para a prevenção e promoção da saúde. Saúde do homem em debate. Rio Janeiro, p. 175-199.

Dotoli F. \& Leão A. (2015). Violência doméstica contra o homem: de agressor a agredido. Rev Ibero-Americana Estud em Educ, v. 10, n. 2, p. 1641-1660. Disponível em: https://periodicos.fclar.unesp.br/iberoamericana/article/view/8341

Ercole F. F. et al. (2014). Integrative review versus systematic review. Reme Rev Min Enferm, v. 18, n. 1, p. 9-12.

Ferreira M. N. X. et al (2019). Care of perpetrators of repeat family violence: An integrative literature review. ACTA Paul Enferm, v. 32, n. 3, p. 334-340. 
Lopes F. M. C. B. et al. (2016). Violência doméstica contra homens: perceções das forças de segurança. Dissertação de mestrado integrado em Psicologia, v. 9, n. 8.

Paviani J. et al. (2007). Cultura, humanismo e globalização. In: Caxias do Sul: Educs, p. 4547.

Rauen F. J. \& Rauen B. M. (2018). Extensão do escopo da lei Maria da Penha a homens vítimas de violência doméstica e familiar em Pelicani. análise pragmático-cognitiva, v. 15, n. $3, \quad$ p. $3153-3169$. 3isponível em: https://periodicos.ufsc.br/index.php/forum/article/view/1984-8412.2018v15n3p3153.

Souza H. C. \& Ferreira L. B. R. (2017). A violência doméstica contra homens no brasil: análise da proteção sócio-jurídica e das formas de enfrentamento. Universidade Federal da Paraíba, v. 6, p. 67-85.

Souza M. T. et al. (2010). Revisão integrativa: o que é e como fazer. Einstein, v. 8, p. 102106. DOI: https://doi.org/10.1590/s1679-45082010rw1134.

\section{How to cite this article (APA format):}

Herculano, Maria Aparecida Feitosa Cândido; Sousa, Allex Alves Sobral de; Sousa, Carmelita Maria Silva; Queiroz, Iasmin Belém Silva; Pimentel, Maria Zildanê Cândido Feitosa; Lima, Maria Nailê Cândido Feitoza dPimentel, João Pedro Cândido; Dominguês, Carolina Cândido; Santana, Willma José de; Luz, Dayse Christina Rodrigues Pereira (2020). Domestic violence against men: simple joy or pure reality? Am. In. Mult. J., Jul to Oct. (9) 5, 266-277.

Received: 04/11/2020;

Accepted: 11/11/2020. 